\title{
Trends in non-metastatic prostate cancer management in the Northern and Yorkshire region of England, 2000-2006
}

\begin{abstract}
L Fairley ${ }^{*, 1}$, M Baker ${ }^{2}$, J Whiteway ${ }^{3}$, W Cross ${ }^{4}$ and D Forman ${ }^{1,5}$
'Northem and Yorkshire Cancer Registry and Information Service, Level 6, Bexley Wing, St James's Institute of Oncology, St James's Hospital, Beckett Street, Leeds, LS9 7TF, UK; 'eeds Teaching Hospitals Trust, Bexley Wing, St James's Institute of Oncology, St James's Hospital, Leeds, LS9 7TF, UK; ${ }^{3}$ North of England Cancer Network, Team View, Fifth Avenue Business Park, Team Valley Trading Estate, Gateshead, Tyne and Wear, NE II OXA, UK; ${ }^{4}$ Pyrah Department of Urology, St James's Hospital, Beckett Street, Leeds, LS9 7TF, UK; ${ }^{5}$ Cancer Epidemiology Group, Centre for Epidemiology and Biostatistics, University of Leeds, Level 6, Bexley Wing, St James's Institute of Oncology, St James's Hospital, Beckett Street, Leeds, LS9 7TF, UK
\end{abstract}

BACKGROUND: Our objective was to analyse variation in non-metastatic prostate cancer management in the Northern and Yorkshire region of England.

METHODS: We included 21334 men aged $\geqslant 55$, diagnosed between 2000 and 2006. Principal treatment received was categorised into radical prostatectomy (1 $1 \%)$, brachytherapy (2\%), external beam radiotherapy (16\%), hormone therapy (42\%) and no treatment (29\%).

RESULTS: The odds ratio (OR) for receiving a radical prostatectomy was 1.53 in 2006 compared with 2000 (95\% Cl I.26- I.86), whereas the $\mathrm{OR}$ for receiving hormone therapy was 0.57 (0.5 I-0.64). Age was strongly associated with treatment received; radical treatments were significantly less likely in men aged $\geqslant 75$ compared with men aged 55-64 years, whereas the odds of receiving hormone therapy or no treatment were significantly higher in the older age group. The OR for receiving radical prostatectomy, brachytherapy or external beam radiotherapy were all significantly lower in the most deprived areas when compared with the most affluent $(0.64(0.55-0.75), 0.32(0.22-0.47)$ and $0.83(0.74-0.94)$, respectively) whereas the OR for receiving hormone therapy was $1.56(1.42-1.71)$.

CONCLUSIONS: This study highlights the variation and inequalities that exist in the management of non-metastatic prostate cancer in the Northern and Yorkshire region of England.

British Journal of Cancer (2009) I 01, | 839- 1845. doi:I0.1038/sj.bjc.6605424 www.bjcancer.com

Published online 10 November 2009

(C) 2009 Cancer Research UK

Keywords: prostate cancer; radical prostatectomy; brachytherapy; radiotherapy; treatment variation

Prostate cancer is the most commonly diagnosed cancer in men in the United Kingdom, accounting for nearly a quarter of all new male cancer diagnoses (Cancer Research UK, 2009). Prostate cancer incidence has increased dramatically over the post 20 years (Majeed et al, 2000; Cancer Research UK, 2009) and much of this is because of prostate-specific antigen (PSA) testing, which has resulted in many diagnoses of prostate cancer that would not have previously been diagnosed (Brewster et al, 2000; Evans and Moller, 2003). Prostate cancer is also the most commonly diagnosed cancer in men throughout Europe (Ferlay et al, 2007) and the United States (SEER, 2009).

Treatments for prostate cancer include radical prostatectomy, radiotherapy (including both brachytherapy and external beam radiotherapy), hormone therapy, active surveillance and watchful waiting. Radical treatments, such as surgery and radiotherapy, can have serious side effects that affect quality of life, such as urinary, bowel and sexual dysfunction. Side effects for hormone treatment

* Correspondence: L Fairley, Bradford Institute for Health Research, Bradford Royal Infirmary, Duckworth Lane, Bradford BD9 6RJ, UK; E-mail: lesley.fairley@bradfordhospitals.nhs.uk

Received 28 April 2009; revised 15 September 2009; accepted 12 October 2009; published online 10 November 2009 include osteoporosis, cardiovascular disease, loss of libido and gynaecomastia. There is no consensus on the best treatment for early prostate cancer (Selley et al, 1997; NICE, 2002, 2008). Improving Outcomes Guidance for Urological Cancers published in 2002 by the National Institute for Clinical Excellence (NICE) (NICE, 2002) recognised that although observation studies suggest that radical treatments can improve long-term survival, these studies are subject to bias in the selection of particular patient groups. Information on treatment complications and quality of life after radical treatment must also be taken into consideration when assessing treatment options. NICE published clinical guidelines for the diagnosis and treatment of prostate cancer in 2008 (NICE, 2008). Selection of treatment for men with localised prostate cancer is based on their risk that is derived from a combination of PSA levels, Gleason score and clinical stage. For example, for men with low-risk localised prostate cancer, the preferred treatment option, as recommended by NICE, is active surveillance; however, other treatment options include prostatectomy, brachytherapy or conformal radiotherapy. However, in clinical practice, treatment decisions are more complex and various studies in the United Kingdom have found that there were wide variations in the management of prostate cancer (Savage et al, 1997; Donovan et al, 1999; Hanna et al, 2002; Payne and Gillatt, 2007). 
Socio-demographic factors that are found to be associated with the treatment received for prostate cancer include ethnicity, socioeconomic status, income and geographical area of residence (Harlan et al, 2001; Bauvin et al, 2003; Cooperberg et al, 2004; Krupski et al, 2005). Results show that patients with low-income or low socio-economic status are less likely to receive surgery or radiotherapy.

In this paper we describe the variation and management of nonmetastatic prostate cancer using data from a population-based cancer registry. We explore the trends between 2000 and 2006 and analyse what factors are associated with treatment received.

\section{MATERIALS AND METHODS}

The Northern and Yorkshire Cancer Registry and Information Service (NYCRIS) is a population-based cancer registry covering a population of approximately 6.7 million people, collecting data on all new diagnoses of cancer within its population. Information collected includes tumour, demographic and treatment information. Data for this analysis were extracted from the NYCRIS database. There were 24946 men diagnosed with prostate cancer between 2000 and 2006, aged $\geqslant 55$ at diagnosis. Men with metastases, including distant nodal involvement, at diagnosis were excluded from the analysis $(n=3281)$. Men who were registered from a death certificate only and men who had a survival time of zero days $(n=224)$ were also excluded from analysis.

The Northern and Yorkshire Cancer Registry and Information Service NYCRIS records treatment planned at diagnosis, and therefore, men on active surveillance or watchful waiting will have no treatment recorded in the cancer registry database although they may go on to receive treatment in the future. From our data we identified the principal treatment received using five different treatment categories: radical prostatectomy, brachytherapy, external beam radiotherapy, hormone treatment and no treatment. A further 103 men were excluded from the study as they did not fit into any of the treatment categories listed; some had chemotherapy recorded as the treatment received and others had different surgery codes recorded. We have included a no treatment group as this consisted of a large percentage of the study population (29\%), although this group includes a mix of patients on active surveillance, watchful waiting and those who actually receive no treatment and we cannot distinguish between these three groups from the data that we have. This resulted in a study population of 21334 men.

Other explanatory variables extracted for each patient were age at diagnosis, year of diagnosis and postcode of residence at diagnosis. This postcode was then used to assign patients to a cancer network of residence and deprivation score. An area-based measure of deprivation, the Index of Multiple Deprivation 2004 (Noble et al, 2004), was used to measure socio-economic status. The Income domain of this index was used in which each patient was assigned a score based on their postcode and these scores were ranked and split into quintiles: quintile 1 contains patients in the most affluent areas and quintile 5 contains patients in the most deprived areas. Patients were also assigned to a Cancer Network based on their postcode of residence at diagnosis. Cancer networks bring together health service commissioners and providers, the voluntary sector and local authorities and are responsible for the delivery of cancer services within a geographical area. There are currently three cancer networks covering the NYCRIS region and these have been used in the analysis presented here: Yorkshire Cancer Network (YCN), Humber and Yorkshire Coast Cancer Network (HYC) and North of England Cancer Network (NECN).

Age-standardised rates per 100000 population for all ages were calculated using the European Standard Population (Office for National Statistics, 1998). Univariate tests of association between the explanatory variables and the principal treatment received were carried out using $\chi^{2}$ test. Multivariate logistic regression was then used to examine the associations between the explanatory variables and each mode of treatment received.

\section{RESULTS}

Overall, the age-standardised incidence rate, standardised to the European standard population for all ages, was 93.5 per 100000 population, and this increased from 83.1 per 100000 in 2000 to 96.6 per 100000 in 2004 (Table 1). There were a total of 21334 cases in our study population after exclusions and the number of these cases diagnosed each year increased from 2572 in 2000 to 3264 in 2006.

Table 2 shows the overall percentage of men receiving each treatment. Table 3 shows the demographic characteristics of the study population by treatment group and Figure 1 shows the principal treatment by year of diagnosis.

Overall, between 2000 and 2006, hormone therapy was the most common mode of treatment (42\%), whereas $29 \%$ of patients received no treatment and $11 \%$ of patients received a radical prostatectomy. The rate of radical prostatectomy increased from $7 \%$ in 2000 to $13 \%$ in 2006 . The brachytherapy rate remained at approximately $2 \%$ over the 7 -year period and the external beam radiotherapy rate increased slightly over time from $14 \%$ in 2000 to $18 \%$ in 2006 . The use of hormone therapy decreased over time from $48 \%$ in 2000 to $32 \%$ in 2006 . The percentage of patients receiving no treatment remained between 27 and $29 \%$ from 2000 to 2005 but increased to $35 \%$ in 2006 .

There were higher percentages of men aged 55-64 and 65-74 years who received all three radical treatments when compared with men aged $\geqslant 75$ years; for men aged $\geqslant 75$ years, $3 \%$ received a radical prostatectomy, $1 \%$ received brachytherapy and $8 \%$ received hormone therapy. Lower percentages of men aged 55-64 years received hormone therapy $(8 \%)$ and no treatment $(14 \%)$ when compared with men aged $\geqslant 65$ years.

There were statistically significant differences in the treatments received by network of residence. Radical prostatectomies were more common in YCN $(14 \%)$ than in HYC $(8 \%)$ and in NECN (9\%). Brachytherapy was also more common in YCN (3\%) than the other two networks. External beam radiotherapy was more common in YCN (18\%) and in HYC (22\%) than in NECN (12\%).

Table I European age-standardised rates (ASR) per 100000 male population and $95 \%$ confidence intervals $(\mathrm{Cl})$ by year for all ages

\begin{tabular}{lcc}
\hline Year & ASR & $\mathbf{9 5 \%} \mathbf{C l}$ \\
\hline 2000 & 83.1 & $(80.2-86.0)$ \\
2001 & 92.9 & $(89.9-96.0)$ \\
2002 & 91.3 & $(88.3-94.3)$ \\
2003 & 95.7 & $(92.6-98.8)$ \\
2004 & 97.8 & $(94.7-100.9)$ \\
2005 & 96.7 & $(93.7-99.8)$ \\
2006 & 96.6 & $(93.6-99.7)$ \\
All years & 93.5 & $(92.4-94.6)$ \\
\hline
\end{tabular}

Table 2 Number and percentage of men receiving each treatment

\begin{tabular}{lrrc}
\hline Treatment & $\boldsymbol{n}$ & \% & $\begin{array}{c}\text { Rate per 100 000 } \\
\text { male population }\end{array}$ \\
\hline Radical prostatectomy & 2240 & 10.5 & 9.9 \\
Brachytherapy & 440 & 2.1 & 1.9 \\
External beam radiotherapy & 3410 & 16.0 & 15.1 \\
Hormone therapy & 8987 & 42.1 & 39.8 \\
No treatment & 6257 & 29.3 & 27.7 \\
\hline
\end{tabular}


Table 3 Demographic characteristics of the study population by treatment group

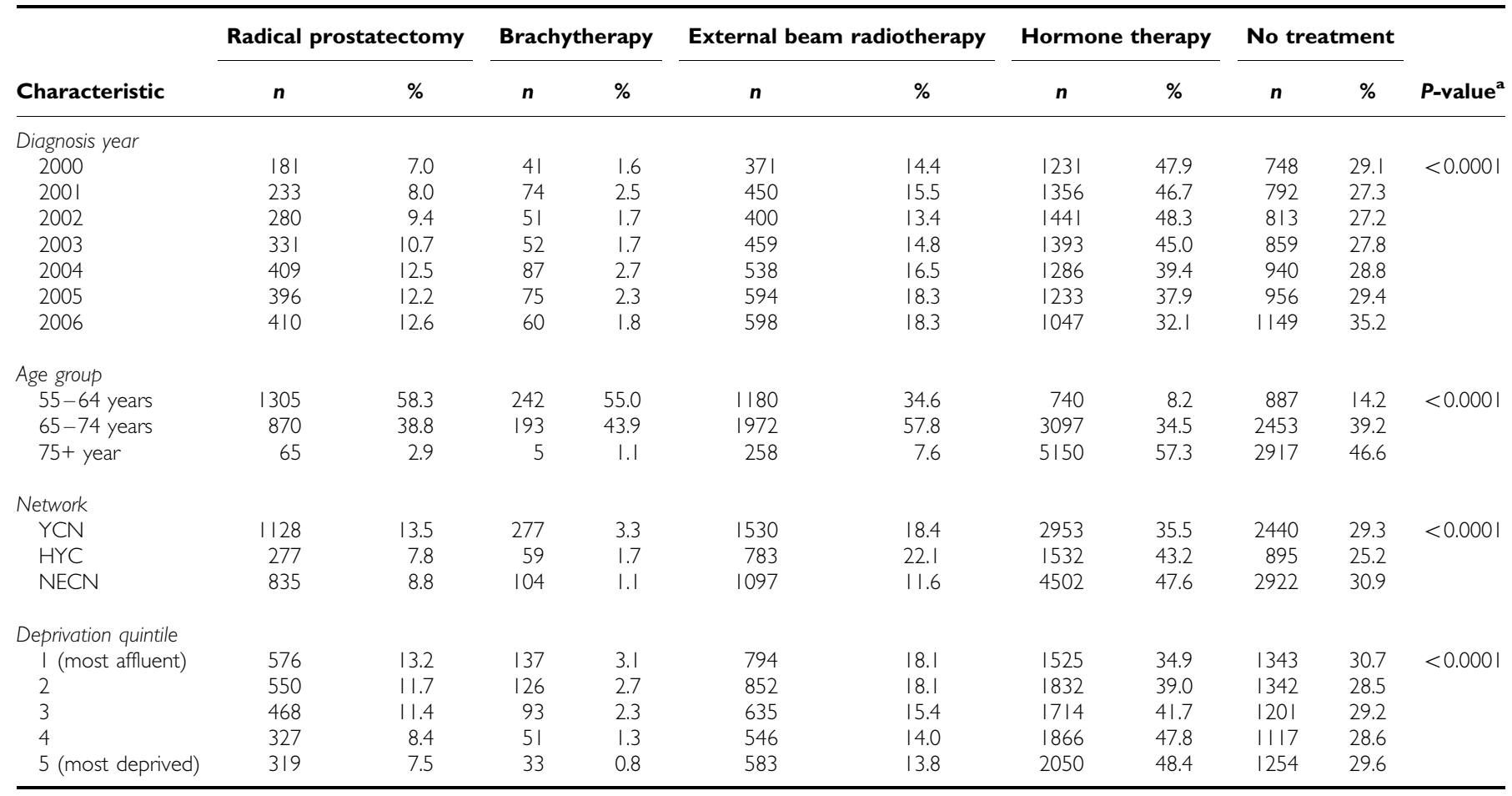

Abbreviations: HYC $=$ Humber and Yorkshire Coast Cancer Network; NECN = North of England Cancer Network; YCN = Yorkshire Cancer Network. ${ }^{a}$ Chi-squared P-value.

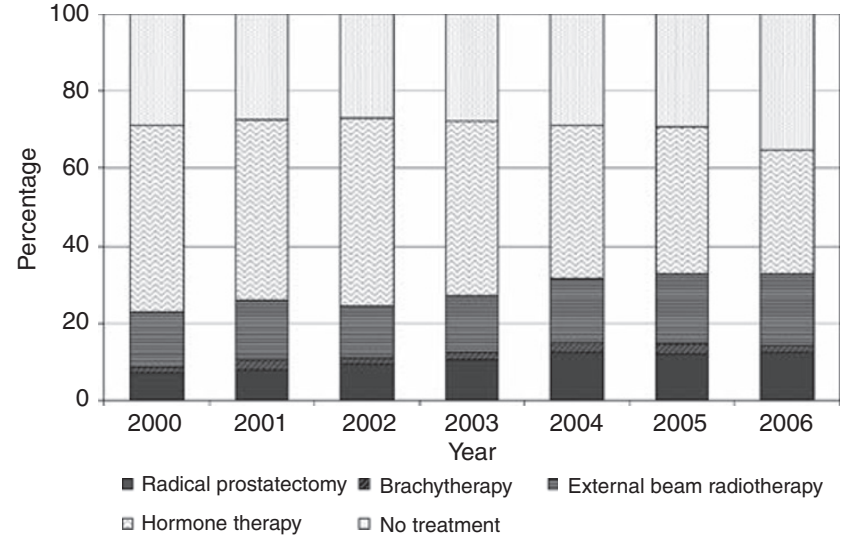

Figure I Principal treatment by year of diagnosis.

Only $35 \%$ of patients in YCN were treated by hormone therapy compared with $43 \%$ of patients in HYC and $48 \%$ in NECN. Fewer men in HYC $(25 \%)$ received no treatment when compared with YCN (29\%) and NECN (31\%).

The treatment received also varied by deprivation quintile. There was a linear trend in the percentage of men who received a radical prostatectomy: $13 \%$ of men in the most affluent areas received this treatment when compared with only $8 \%$ of men in the most deprived areas. A similar socio-economic gradient was also observed for brachytherapy and external beam radiotherapy: rates were highest in the most affluent areas and lowest in the most deprived areas. Only $35 \%$ of men in the most affluent areas received hormone therapy compared with $48 \%$ of men in the most deprived areas. There was not much difference in the percentage of men who received no treatment by deprivation quintile. Figure 2 also shows the principal treatment received by deprivation quintile.

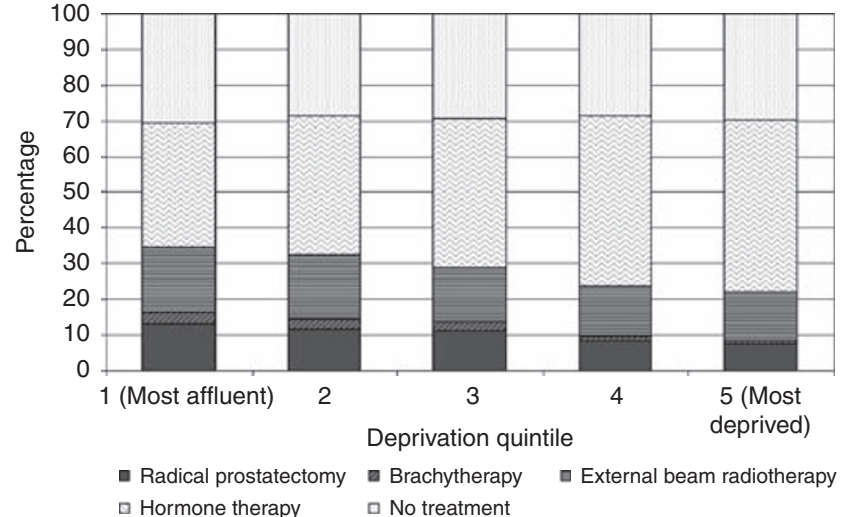

Figure 2 Principal treatment by deprivation quintile.

Table 4 shows the results from the multivariate logistic regression models.

Men diagnosed with prostate cancer in 2006 were $53 \%$ more likely to receive a radical prostatectomy than men diagnosed in 2000 (odds ratio $(\mathrm{OR})=1.53,95 \%$ confidence interval $(\mathrm{CI}) 1.26$ 1.86). There were no statistically significant differences in the likelihood of receiving brachytherapy or external beam radiotherapy over time. Men diagnosed in 2006 were $43 \%$ less likely to have hormone treatment than men diagnosed in $2000(\mathrm{OR}=0.57$, $95 \%$ CI $0.51-0.64)$. The odds of having no treatment were $42 \%$ higher in 2006 when compared with $2000(\mathrm{OR}=1.42,95 \% \mathrm{CI}$ $1.27-1.59$ ).

There was a very strong association between age and treatment received. The odds of having a radical prostatectomy, brachytherapy or external beam radiotherapy decreased as age at diagnosis increased. The OR for men aged $\geqslant 75$ years, compared 
Table 4 Association between treatment received and demographic variables, odds ratios (OR) and 95\% confidence intervals (Cl). Results from multivariate logistic regression

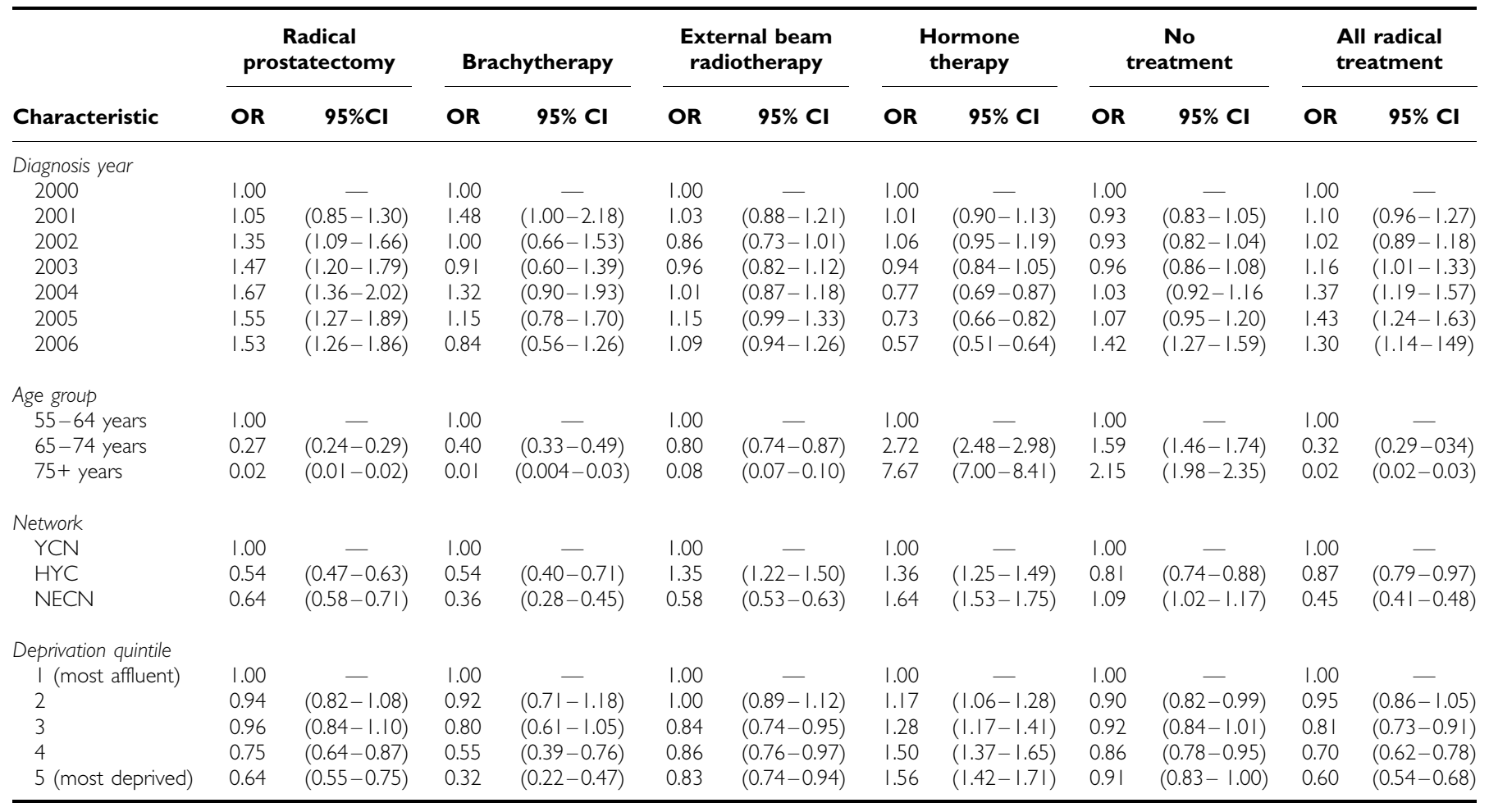

Abbreviations: HYC = Humber and Yorkshire Coast Cancer Network; NECN = North of England Cancer Network; YCN = Yorkshire Cancer Network.

with men aged 55-64 years, for receiving a radical prostatectomy were 0.02 (95\% CI $0.01-0.02)$, for receiving a brachytherapy were 0.01 (95\% CI $0.004-0.03)$ and for receiving an external beam radiotherapy were 0.08 (95\% CI $0.07-0.10)$. The odds of receiving hormone therapy, and no treatment significantly increased as age at diagnosis increased. The OR for men aged $\geqslant 75$ years, compared with men aged 55-64 years, for receiving hormone therapy were 7.67 (95\% CI $7.00-8.41)$ and for receiving no treatment were 2.15 (95\% CI $1.98-2.35)$.

For all treatment modalities there were statistically significant differences across the networks. Compared with YCN, radical prostatectomy and brachytherapy were less likely in HYC $(\mathrm{OR}=0.54,95 \%$ CI $0.47-0.63$ and $\mathrm{OR}=0.54,95 \%$ CI $0.40-0.71)$ and in NECN $(\mathrm{OR}=0.64,95 \% \mathrm{CI} 0.58-0.71$ and $\mathrm{OR}=0.36,95 \% \mathrm{CI}$ $0.28-0.45)$. External beam radiotherapy was more likely in HYC $(\mathrm{OR}=1.35,95 \% \mathrm{CI} 1.22-1.50)$ and less likely in NECN $(\mathrm{OR}=0.58$, $95 \%$ CI $0.53-0.63)$ compared with YCN. The odds of receiving hormone therapy were more likely in both HYC and NECN compared with YCN $(\mathrm{OR}=1.36,95 \%$ CI $1.25-1.49$ and $\mathrm{OR}=1.64$, $95 \%$ CI $1.53-1.75)$. The odd of receiving no treatment were significantly lower in HYC than in YCN $(\mathrm{OR}=0.81,95 \%$ CI $0.74-$ $0.88)$ and significantly higher in NECN than in $\mathrm{YCN}(\mathrm{OR}=1.09$, $95 \%$ CI $1.02-1.17$ ).

The odds of receiving a radical prostatectomy, brachytherapy or external beam radiotherapy were all significantly lower in the most deprived areas compared with the most affluent $(\mathrm{OR}=0.64,95 \%$ CI $0.55-0.75 ; \mathrm{OR}=0.32,95 \%$ CI $0.22-0.47$; and $\mathrm{OR}=0.83,95 \% \mathrm{CI}$ $0.74-0.94$, respectively). The odds of receiving hormone therapy increased as deprivation increased $(\mathrm{OR}=1.56,95 \% \mathrm{CI} 1.42-1.71)$ for most deprived areas compared with most affluent areas. The association between deprivation and receiving no treatment was of borderline statistical significance $(P=0.05)$; the magnitude of the effect was similar in all deprivation quintiles relative to the most affluent quintile but only statistically significantly different in quintiles 2 and $4(\mathrm{OR}=0.90,95 \%$ CI $0.82-0.99$ and $\mathrm{OR}=0.86$, $95 \%$ CI $0.78-0.95$ respectively).

\section{DISCUSSION}

Our results show that there are variations in the modality of treatment received in men with non-metastatic prostate cancer in the Northern and Yorkshire region. Younger men were more likely to receive radical treatments, radical prostatectomy, brachytherapy and external beam radiotherapy, as were men from the more affluent areas, whereas older men and men from the more deprived areas were more likely to receive hormone therapy. There were also differences by cancer network of residence. Over the study period, the rates of radical prostatectomies increased whereas the rate of hormone therapy decreased.

Socio-demographic factors, such as age, ethnicity, geographic region of residence and income, have all been found to be associated with prostate cancer treatment elsewhere, including studies from the United States and France (Harlan et al, 2001; Bauvin et al, 2003; Cooperberg et al, 2004; Krupski et al, 2005). We also found significant associations between treatment and age, deprivation and geographic region of residence. Radical treatments were less likely in the older population and men from deprived areas and may be explained by differences in life expectancy, with both these groups having shorter life expectancy (Bajekal, 2005).

\section{Strengths and limitations of the study}

One of the main strength of this study is that it is population based and includes data from over 21000 cases, and therefore produced statistically robust estimates. It is also recognised that the coding 
of treatment procedures were of high quality and well recorded with the Northern and Yorkshire Cancer Registry and Information Service (United Kingdom Association of Cancer Registries, 2009).

One of the main limitations of this study is that we do not have data available on stage and grade of the tumours, or PSA levels, as these data items are not routinely collected by NYCRIS. The recently established National Cancer Intelligence Network aims to develop a national cancer data repository, involving linking the cancer registration data with other data sources. Work to link urological data from cancer registries to Hospital Episode Statistics and data from the clinical database of the British Association of Urological Surgeons (BAUS) is underway (Ayres et al, 2008) and data sets such as these will provide valuable information on stage and grade so that full case-mix adjustment can be made.

The recent increase in PSA testing, which has been found to be more common in affluent areas (Melia et al, 2004; Rowan et al, 2008), has resulted in many more cancers being diagnosed earlier and these cancers may be more likely to receive radical treatments. Schröder et al (2009) found that PSA-based screening reduced the rate of death from prostate cancer by $20 \%$ but was associated with a high risk of diagnosing many men who would not have clinical symptoms during their lifetime.

The other main limitation of this study is regarding the use and interpretation of the no treatment group. This group contains all patients who had no record of receiving any treatment. The routine collection of data within the cancer registry includes treatment intent at diagnosis. The no treatment group in our study will include men on active surveillance and watchful waiting and some of this group may go on to receive some form of treatment; however, this will not be recorded on the cancer registry database. This group will also include patients who actually received no treatment and there may also be some other cases in which we do not know whether the patient received any treatment. Therefore, results concerning this group should be interpreted with caution. We have excluded all records only notified from Death Certificates or with zero survival ( $0.9 \%$ of study population), thus reducing bias from this source.

The percentage of men who received no treatment in 2006 increased to $35 \%$ compared with $27-29 \%$ between 2000 and 2005 . This increase was observed across all cancer networks as more men may be opting for deferred treatment. This increase may just be because of chance and further monitoring of trends is required and when national data become available, trends across other areas can also be analysed.

There are important differences between active surveillance and watchful waiting, although patients on both treatment options are spared the side effects of unnecessary treatment. Active surveillance is an option for men who are suitable for radical treatment but for whatever reasons choose to delay treatment; however, if there are signs of tumour progression, then radical treatment may be offered. Watchful waiting is an option for men not suitable for radical treatments, such as older men or those with poor general health, or some men presenting with asymptomatic advanced disease; if the cancer progresses then these men will generally receive hormone therapy. Our study does not allow us to distinguish between these two groups. However, there was some evidence that men from more deprived areas were less likely to receive no treatment but with borderline significance. Treatment decisions, including the option of active surveillance or watchful waiting, should be made taking into consideration the needs and preferences of the patients and after careful consideration of the options and discussions with their healthcare professionals (NICE, 2008). These decisions could be related to educational levels and the deliberation to choose to delay treatment may be easier and more likely in men from better educated groups. Kane et al (2003) found that the education levels of the patients were predictive of primary treatment for prostate cancer but the effect of education depends on age.

\section{Treatment options}

The use of radical prostatectomy increased nearly 20 -fold between 1991 and 1999 in England (Oliver et al, 2003), and in our study population the odds of having a radical prostatectomy increased significantly by $53 \%$ from 2000 to 2006 . The rise in surgery may be because of an increase in the numbers of surgeons with the technical ability and enthusiasm to perform this procedure. Surgery is an option for men whose tumours are confined to the prostate and who are expected to live for at least 10 years (NICE, 2002). It can cause significant complications that affect quality of life, such as impotence and incontinence; generally, it will be the fittest men with localised prostate cancer who are selected for surgery. We found a very strong association between age and surgery. We also found that men from the most deprived areas were $36 \%$ less likely to have a radical prostatectomy than men from the most affluent areas. Co-morbidity could explain part of this relationship as we would expect greater levels of comorbidities in men in the more deprived areas and therefore these men will be less likely to be suitable for surgery. However, a study in the Netherlands found that for prostate cancer patients there was no association between socio-economic status and levels of co-morbidity (Schrijvers et al, 1997). A study in Western Australia found that men who received radical prostatectomy had less co-morbidities and were more socio-economically advantaged (Hall et al, 2005). Although radiotherapy is non-invasive, it shares most of the complications and side effects that follow surgery. Therefore, the extent that co-morbidities may have in explaining the inequalities that we observed in external beam radiotherapy, in which men from more deprived areas were less likely to receive external beam radiotherapy, is not clear.

Brachytherapy is an option suitable for men with smaller prostates who may choose any other radical treatment, including patients who are not suitable for surgery (Ash et al, 1998). The use of brachytherapy in general has become more common throughout Europe (Guedea et al, 2007). This was the least common mode of treatment received in our study population. We did, however, find a large deprivation gap in the odds of getting brachytherapy; men from the most deprived areas were $68 \%$ less likely to receive this form of treatment than men from the most affluent areas after adjustment for age and network, suggesting a lack of access to this treatment for men from socially deprived areas. The odds of receiving brachytherapy were also reduced in older men when compared with younger men. Brachytherapy can be technically challenging in larger prostate glands, although some centres may downsize the gland with hormones before brachytherapy. The prostate gland increases in size with age and hence this form of treatment may not be suitable for older men.

Hormone therapy is the recommended treatment for men with locally advanced prostate cancer either with or without external beam radiotherapy (NICE, 2002). A recent study by Widmark et al (2009) found that the addition of local radiotherapy to endocrine treatment halved the 10-year prostate cancer-specific mortality. Hormone therapy was the most common form of treatment received in our study population and was more common among older men and men from more deprived areas. This may suggest that men from deprived areas present with more advanced cancers and that radical treatment might not be suitable for these patients. Without information on stage, we are unable to confirm this. However, over time we did see that the hormone treatment rate decreased from $48 \%$ to $32 \%$, and over this same time period the rate of surgery increased.

Woods et al (2006) reviewed the origins of socio-economic inequalities in cancer survival and found many studies that showed differential treatment between socio-economic groups. We also found that men from more deprived areas were less likely to receive radical treatments and more likely to receive hormone treatment. For prostate cancer there is a lower likelihood of 
asymptomatic screening by GPs in less advantaged areas and men from more deprived areas are less likely to be offered radical treatments.

\section{Other studies}

Radical treatment for prostate cancer can cause serious side effects that will affect quality of life, such as urinary, bowel and sexual dysfunction; therefore, it is important to assess which treatment is optimal for men with prostate cancer. A few studies have compared survival from different treatment groups in terms of prostate cancer-specific survival and overall survival. A Scandinavian trial, which compared radical prostatectomy and watchful waiting, found that radical prostatectomy reduces disease-specific mortality and overall mortality after 10 years (Bill-Axelson et al, 2005). A study, which compared prostatectomy, brachytherapy and no definitive treatment, found that men treated with either the prostatectomy or brachytherapy had better survival (Tward et al, 2006). Other case series studies have shown that biochemical failure rates are similar for radical prostatectomy, brachytherapy and external beam radiotherapy (Kupelian et al, 2004; Potters et al, 2004). The Prostate Cancer Outcomes Study found that after 5 years men treated by radical prostatectomy experienced worse urinary incontinence than men treated with external beam radiotherapy; however, both groups had similar overall sexual dysfunction (Potosky et al, 2004). Other studies have assessed health-related quality of life, such as sexual functioning, urinary incontinence and bowel functioning, and found that this varies by treatment (Buron et al, 2007; Litwin et al, 2007; Ferrer et al, 2008; Sanda et al, 2008).

\section{Network differences in treatment received}

We found that there were differences between the Cancer Networks in the treatment men received. This will be partly because of the local availability of the treatment options - brachytherapy was only available in Leeds and Newcastle during our study period. The absence of any clarity about the right treatment for some men inevitably leads to variation in practice.

Another factor that may influence treatment decisions and effect on the geographic inequalities that we observed are the waiting times for treatments such as radiotherapy and surgery. Some of the differences between networks in the treatment rates that we observed may be because of differences in waiting times. The NHS Cancer Plan published in 2000 (Department of Health, 2000) set out standards for cancer waiting times, including a 31-day standard from diagnosis/decision to treat to first treatment. The Cancer Reform Strategy (Department of Health, 2007) extended this standard to cover all cancer treatments. The largest effect that this will have is on radiotherapy delivery, in which increased capacity will be needed in some areas, and the implementation date for the application of this target to patients who receive radiotherapy will be consequently delayed. If all cancer networks are able to meet this standard, then the patient's choice of treatment should be less influenced by treatment delays.

In the United Kingdom, the Prostate Testing for Cancer and Treatment (ProtecT) trial has been set up to evaluate treatments for localised prostate cancer (http://www.epi.bris.ac.uk/protect/). This study invites asymptomatic men aged 50-69 to test for prostate cancer using PSA testing. Those who have raised agerelated PSA levels are offered a transrectal ultrasound-guided biopsy and, when they are found to have localised prostate cancer, they are asked to consent to a three-armed treatment trial of prostatectomy, radiotherapy or active monitoring. Those who did not consent to randomisation could select one of the treatments. Recruitment began in 2001 and continued until 2008, with followup planned for 10-15 years. Studies such as this will provide vital information about which treatment is best for men with localised prostate cancer. Over the study period in our analysis, Newcastle was the major recruiting centre for this study with Leeds joining around 2005, and hence some of the men in our study would have been involved in this study. Results so far show that patients who self-selected active monitoring were more affluent than those randomised to that treatment (Mills et al, 2006). Levels of PSA testing are more common in more affluent areas of England and Wales (Melia et al, 2004; Rowan et al, 2008), and there are associations between affluence, PSA testing and treatment choices.

One of the key goals of the recent Department of Health Cancer Reform Strategy is to reduce inequalities in cancer incidence, access to services and outcomes (Department of Health, 2007). Inequalities in prostate cancer incidence have been reported for England with higher incidence rates observed in the most affluent areas (National Cancer Intelligence Network, 2008). Much of the recent increase in prostate cancer incidence is because of the increased use of PSA testing, resulting in the diagnosis of many asymptomatic cancers that would never previously have been diagnosed in life. There are wide variations in rates of PSA testing by GP practice (Gavin et al, 2004) and there is evidence that PSA testing is more common in more affluent areas in England and Wales (Melia et al, 2004; Rowan et al, 2008). There are also inequalities in prostate cancer survival and the deprivation gap in survival has increased between the late 1980s and late 1990s (Rowan et al, 2008), although much of this will be influenced by variations in PSA testing. We have also found socio-economic inequalities in the treatment received for men diagnosed with prostate cancer.

\section{CONCLUSIONS}

This study highlights the wide variation that exists in the management of non-metastatic prostate cancer in the Northern and Yorkshire region of England. We have used population-based cancer registry data and found that the principal method of treatment received was found to vary by age at diagnosis, cancer network of residence and deprivation quintile.

\section{REFERENCES}

Ash D, Bottomley DM, Carey BM (1998) Prostate brachytherapy. Prostate Cancer Prostatic Dis 1: $185-188$

Ayres B, McPhail S, Persad R, Cottier B, Verne J, Gillatt D (2008) The British Association of Urological Surgeons section of oncology urological cancer observatory project. BJU Int 101(Suppl 1): 1-45

Bajekal M (2005) Healthy life expectancy by area deprivation: magnitude and trends in England, 1994-1999. Health Stat Q 25: 18-27

Bauvin E, Soulie M, Menegoz F, Mace-Lesec'h J, Buemi A, Velten M, Villers A, Grosclaude P (2003) Medical and non-medical determinants of prostate cancer management: a population based study. Eur J Cancer 39: $2364-2371$
Bill-Axelson A, Holmberg L, Ruutu M, Haggman M, Andersson SO, Bratell S, Spangberg A, Busch C, Nordling S, Garmo H, Palmgren J, Adami HO, Norlen BJ, Johansson JE (2005) Radical prostatectomy versus watchful waiting in early prostate cancer. $N$ Engl J Med 352: $1977-1984$

Brewster DH, Fraser LA, Harris V, Black RJ (2000) Rising incidence of prostate cancer in Scotland: increased risk or increased detection. BJU Int 85: $463-473$

Buron C, Le Vu B, Cosset JM, Pommier P, Peiffert D, Delannes M, Flam T, Guerif S, Salem N, Chauveinc L, Livartowski A (2007) Brachytherapy versus prostatectomy in localized prostate cancer: results of a French 
multicenter prospective medico-economic study. Int J Radiat Oncol Biol Phys 67: 812-822

Cancer Research UK (2009) UK Prostate Cancer incidence statistics. http:// info.cancerresearchuk.org/cancerstats/types/prostate/incidence/ (accessed August 2009)

Cooperberg MR, Lubeck DP, Meng MV, Mehta SS, Carroll PR (2004) The changing face of low-risk prostate cancer: trends in clinical presentation and primary management. J Clin Oncol 22: 2141-2149

Department of Health (2000) The NHS Cancer Plan

Department of Health (2007) Cancer Reform Strategy

Donovan JL, Frankel SJ, Faulkner A, Selly S, Gillatt D, Hamdy FC (1999) Dilemmas in treating early prostate cancer: the evidence and a questionnaire survey of consultant urologists in the United Kingdom. BMJ 318: 299-300

Evans HS, Moller H (2003) Recent trends in prostate cancer incidence and mortality in Southeast England. Eur Urol 43: 337-341

Ferlay J, Autier P, Boniol M, Heanue M, Colombet M, Boyle P (2007) Estimates of the cancer incidence and mortality in Europe in 2006. Ann Oncol 18: $581-592$

Ferrer M, Suárez JF, Guedea F, Fernández P, Macías V, Mariño A, Hervas A, Herruzo I, Ortiz MJ, Villavicencio H, Craven-Bratle J, Garin O, Aguiló F, Multicentric Spanish Group of Clinically Localized Prostate Cancer (2008) Health-related quality of life 2 years after treatment with radical prostatectomy, prostate brachytherapy, or external beam radiotherapy in patients with clinically localized prostate cancer. Int J Radiat Oncol Biol Phys 72: $421-432$

Gavin A, McCarron P, Middleton RJ, Savage G, Catney D, O’Reilly D, Keane PF, Murray LJ (2004) Evidence of prostate cancer screening in a UK region. BJU Int 93: 730-734

Guedea F, Ellison T, Venselaar J, Borras JM, Hoskin P, Poetter R, Heeren G, Nisin R, François G, Mazeron JJ, Limbergen EV, Ventura M, Taillet M, Cottier B (2007) Overview of brachytherapy resources in Europe: a survey of patterns of care study for brachytherapy in Europe. Radiother Oncol 82: $50-54$

Hall SE, Holman CD, Wisniewski ZS, Semmens J (2005) Prostate cancer: socio-economic, geographical and private-health insurance effects on care and survival. BJU Int 95: 51-58

Hanna CL, Mason MD, Donovan JL, Barber JP (2002) Clinical oncologists favour radical radiotherapy for localised prostate cancer: a questionnaire survey. BJU Int 90: 558-560

Harlan LC, Potosky A, Gilliland FD, Hoffman R, Albertsen PC, Hamilton AS, Eley JW, Stanford JL, Stephenson RA (2001) Factors associated with initial therapy for clinically localized prostate cancer: Prostate Cancer Outcomes Study. J Natl Cancer Inst 93: 1864-1871

Kane CJ, Lubeck DP, Knight SJ, Spitalny M, Downs TM, Grossfeld GD, Pasta DJ, Mehta SS, Carroll PR (2003) Impact of patient educational level on treatment for patients with prostate cancer: data from CaPSURE. Urology 62: 1035-1039

Krupski TL, Kwan L, Afifi AA, Litwin MS (2005) Geographic and socioeconomic variation in the treatment of prostate cancer. J Clin Oncol 23: $7881-7888$

Kupelian PA, Potters L, Khuntia D, Ciezki JP, Reddy CA, Reuther AM, Carlson TP, Klein EA (2004) Radical prostatectomy, external beam radiotherapy $<72 \mathrm{~Gy}$, external beam radiotherapy $>$ or $=72 \mathrm{~Gy}$, permanent seed implantation, or combined seeds/external beam radiotherapy for stage T1-T2 prostate cancer. Int J Radiat Oncol Biol Phys 58: $25-33$

Litwin MS, Gore JL, Kwan L, Brandeis JM, Lee SP, Withers HR, Reiter RE (2007) Quality of life after surgery, external beam irradiation, or brachytherapy for early-stage prostate cancer. Cancer 109: 2239-2247

Majeed A, Babb P, Jones J, Quinn M (2000) Trends in prostate cancer incidence, mortality and survival in England and Wales 1971-1998. BJU Int 85: $1058-1062$

Melia J, Moss S, Johns L (2004) Rates of prostate-specific antigen testing in general practice in England and Wales in asymptomatic and symptomatic patients: a cross-sectional study. BJU Int 94: 51-56

Mills N, Metcalfe C, Ronsmans C, Davis M, Lane JA, Strene JAC, Peters TJ, Hamdy FC, Neal DE, Donovan JL (2006) A comparison of sociodemographic and psychological factors between patients consenting to randomisation and those selecting treatment (the Protec $\mathrm{T}$ study). Contemp Clin Trials 27: 413-419

National Cancer Intelligence Network (2008) England, 1995-2004.

National Institute for Clinical Excellence (2002) Guidance on Cancer Services: Improving Outcomes in Urological Cancers-The Manual

National Institute for Clinical Excellence (2008) NICE Clinical Guideline 58. Prostate Cancer: Diagnosis and Treatment

Noble M, Wright G, Dibben C, Smith GAN, McLennan D, Anttila C, Barnes H, Mokhtar C, Noble S, Avenell D, Gardner J, Covizzi I, Lloyd M (2004) The English Indices of Deprivation 2004 (revised) Report to the Office of the Deputy Prime Minister London: Neighbourhood Renewal Unit http://www.communities.gov.uk/pub/446/Indicesofdeprivation2004revised id1128446.pdf

Office for National Statistics (ONS) (1998). Distribution of the European standard population. http://www.statistics.gov.uk/StatBase/xsdataset. asp? $v \operatorname{lnk}=1260 \&$ More $=\mathrm{Y}$ (accessed February 2009)

Oliver SE, Donovan JL, Peters TJ, Frankel S, Hamdy FC, Neal DE (2003) Recent trends in the use of radical prostatectomy in England: the epidemiology of diffusion. BJU Int 91: 331-336

Payne HA, Gillatt DA (2007) Differences and commonalities in the management of locally advanced prostate cancer: results from a survey of oncologists and urologists in the UK. BJU Int 99: 545-553

Potosky AL, Davis WW, Hoffman RM, Stanford JL, Stephenson RA, Penson DF, Harlan LC (2004) Five-year outcomes after prostatectomy or radiotherapy for prostate cancer: the Prostate Cancer Outcomes study. J Natl Cancer Inst 96: 1358 - 1367

Potters L, Klein EA, Kattan MW, Reddy CA, Ciezki JP, Reuther AM, Kupelian PA (2004) Monotherapy for stage T1-T2 prostate cancer: radical prostatectomy, external beam radiotherapy, or permanent seed implantation. Radiother Oncol 71: 29-33

Prostate Testing for Cancer and Treatment (ProtecT). http://www. epi.bris.ac.uk/protect/ (accessed February 2009)

Rowan S, Rachet B, Alexe DM, Cooper N, Coleman MP (2008) Survival from prostate cancer in England and Wales up to 2001. Br J Cancer 99: S75 - S77 Sanda MG, Dunn RL, Michalski J, Sandler HM, Northouse L, Hembroff L, Lin X, Greenfield TK, Litwin MS, Saigal CS, Mahadevan A, Klein E, Kibel A, Pisters LL, Kuban D, Kaplan I, Wood D, Ciezki J, Shah N, Wei JT (2008) Quality of life and satisfaction with outcome among prostatecancer survivors. $N$ Engl J Med 358: 1250 - 1261

Savage P, Bates C, Abel P, Waxman J (1997) British urological surgery practice: 1. Prostate cancer. $\mathrm{Br}$ J Urol 79: 749-755

Schrijvers CTM, Coebergh JWW, Mackenbach JP (1997) Socioeconomic status and comorbidity among newly diagnosed cancer patients. Cancer 80: $1482-1488$

Schröder FH, Hugosson J, Roobol MJ, Tammela TL, Ciatto S, Nelen V, Kwiatkowski M, Lujan M, Lilja H, Zappa M, Denis LJ, Recker F, Berenguer A, Määttänen L, Bangma CH, Aus G, Villers A, Rebillard X, van der Kwast T, Blijenberg BG, Moss SM, de Koning HJ, Auvinen A, ERSPC Investigators (2009) Screening and prostate-cancer mortality in a randomized European study. N Engl J Med 26: 1320 - 1328

SEER Cancer Statistics Review. http://seer.cancer.gov/csr/1975_2006/ index.html (Accessed August 2009)

Selley S, Donovan J, Faulkner A, Coast J, Gillatt D (1997) Diagnosis, management and screening of early localised prostate cancer. Health Technol Assess 1(2): 37.

Tward JD, Lee CM, Pappas LM, Szabo A, Gaffney DK, Shrieve DC (2006) Survival of men with clinically localized prostate cancer treated with prostatectomy, brachytherapy or no definitive treatment. Impact of age at diagnosis. Cancer 107: $2392-2400$

United Kingdom Association of Cancer Registries (UKACR). Data quality. http://82.110.76.19/quality/ (Accessed September 2009)

Widmark A, Klepp O, Solberg A, Damber JE, Angelsen A, Fransson P, Lund JA, Tasdemir I, Hoyer M, Wiklund F, Fosså SD, Scandinavian Prostate Cancer Group Study 7, Swedish Association for Urological Oncology 3 (2009) Endocrine treatment, with or without radiotherapy, in locally advanced prostate cancer (SPCG-7/SFUO-3): an open randomised phase III trial. Lancet 373: $301-308$

Woods LM, Rachet B, Coleman MP (2006) Origins of socio-economic inequalities in cancer survival: a review. Ann Oncol 17: 5-19 